EGU21-9713, updated on 01 Feb 2022

https://doi.org/10.5194/egusphere-egu21-9713

EGU General Assembly 2021

(c) Author(s) 2022. This work is distributed under

the Creative Commons Attribution 4.0 License.

\title{
Long-term seafloor morphological changes generated by bottom trawling on the northern Catalan continental shelf (NW Mediterranean)
}

Ruth Durán ${ }^{1,2}$, Pere Puig ${ }^{2}$, Araceli Muñoz ${ }^{3}$, Claudio Lo lacono² ${ }^{2}$ Jorge Guillén ${ }^{2}$, Aaron Micallef ${ }^{1}$, and Albert Palanques ${ }^{2}$

${ }^{1}$ University of Malta, Msida, Malta (ruth.duran@um.edu.mt)

${ }^{2}$ Marine Sciences Institute, CSIC, Barcelona, Spain

${ }^{3}$ TragsauSGP, Madrid, Spain

The north-western Mediterranean continental margin is one of the few regions in the world where bottom trawling has been continuously practised since several decades. Among the existing trawling techniques, the one practised on this region is the "otter trawling", which has a strong impact on the seafloor morphology via scraping and ploughing, especially on muddy substrates. High-resolution multibeam bathymetry and backscatter data, side scan sonar images, sediment cores and satellite based Vessel Monitoring System (VMS) data have been integrated to investigate the impact of bottom trawling on the seafloor morphology of the northern Catalan continental shelf (NW Mediterranean). Satellite-based navigation tracks from bottom trawlers operating in the study area during 6 years (2006-2011) reveal the spatial distribution of fishing grounds and the occurrence of an intense trawling effort around the 50-60 m isobaths, since trawling is banned at shallow depths. Backscatter imagery shows a narrow (120-250 m wide) and discontinuous high backscatter facies along this depth range, extending parallel to the coastline for more than $40 \mathrm{~km}$ from Portbou to l'Estartit. In the bathymetric data, this high backscatter region also coincides with an abrupt change in the mean seafloor gradient (from $0.8^{\circ}$ in the inner shelf to $0.4^{\circ}$ in the middle shelf), or locally with a narrow (50-150 m wide) slightly depressed (0.2-0.6 m deep) channeled morphology. Side-scan sonar images display high density of trawl marks generated by fishing gears in this area. Further offshore, scattered narrower trawl hauls are also observed on the middle shelf (60-90 m deep), where they can be traced across several thousands of meters. Sediment cores retrieved from the area of high backscatter and largest trawling intensity display sediment coarsening in the upper layers $(0-4 \mathrm{~cm})$ caused by winnowing of finer fractions. These findings demonstrate that chronic stirring, mixing and erosion of surface sediments induced by recurrent trawling persisting over the same fishing grounds can cause long-term morphological and sedimentary changes on the continental shelf seafloor.

This study has received funding from the ABIDES (Assessment of Bottom-trawling Impacts in the Deep-sea Sediments) Spanish Research Project (CTM2015-65142-R) and the European Union's Horizon 2020 research and innovation programme under Marie Sklodowska-Curie grant agreement No. 867471. Additional funds were provided by the Generalitat de Catalunya 
Generalitat de Catalunya (2017 SGR-663 and -1588) and by the Spanish Research Project ABRIC (RTI2018-096434-B-I00). This work is contributing to the ICM's 'Center of Excellence' Severo Ochoa (CEX2019-000928-S). The authors wish to thank the Secretaría General de Pesca and Tragsa for the 2004 Espace Project dataset. 